\title{
Measuring the Impact of Social Support on Dietary Behavior: Assessing Techniques and Calling for the Use of Daily Diaries
}

\author{
Ana DiGiovanni and Emily Balcetis* \\ Department of Psychology, New York University, USA
}

Submission: April 03, 2018, 2018; Published: July 17, 2018

*Corresponding author: Emily Balcetis, Department of Psychology, New York University, USA, Email: emilybalcetis@nyu.edu

\section{Introduction}

Establishing good health is a concern for many. In 2016, more than 57 million Americans held memberships at gym facilities [1]. Industry analysts estimated that health club revenues, in the year 2015 , stood at $\$ 25.8$ billion, in part due to the health goals held by patrons [2]. At any given point in time, more than $50 \%$ of women are dieting and almost $90 \%$ of teenagers report doing so regularly [3]. Yet, almost as common as possessing a health goal is the inability to successfully see it through. Currently, over two-thirds of Americans are either overweight or obese, and these numbers are rising. It is predicted that the United States will have an obesity rate of $42 \%$ in 2030 [4]. While the United States stands as the country with the highest rates of obesity, it is not alone in experiencing a health crisis; on average $20 \%$ of the populations of all 35 member countries in the Organization for Economic Co-operation and Development are obese [5]. How can people reduce the discrepancy between intention and action? While the possibilities are many, we focus on the influence of social support on health-related decision making. We review insights gained from daily diary and longitudinal methods, and offer suggestions for research in this area.

Social support, generally, facilitates beneficial long-term health outcomes. Much research demonstrates the positive effects of social support on reducing morbidity and mortality, depression, and chronic illness [6-8]. Close others offer assistance in stressful times to improve acute symptoms and longstanding health risks, habitual choices, or far-reaching disorders. However, there is less known about how social support influences the daily decisions people make about what they eat and how they exercise. Chronic conditions are the result of daily decisions that accumulate over time. Modeling long-term health outcomes requires, then, an understanding of the choices people make people make each day and the factors that influence these momentary decisions. As a result, to advance the understanding of the processes by which social support influences health, it is advantageous to both narrow the scope of inquiry but also extend it over time, exploring the impact of support on interim decision-making, and doing so longitudinally.

At present, the vast majority of research in this area models the impact of social support on health, with both constructs defined at broad, high-levels of description. Specifically, the predominant tactic is to investigate perceptions of social support reported by recipients as they reflect on the course of their recent life, and give summary statements of their recent experiences.For instance, questionnaires assessing perceived social support often ask participants to reflect on extended periods of time, such as the last three months, and recall the prevalence of others' attempts to support or sabotage one's own health-related behaviors during that timeframe [9]. Perceived social support then indexes gestalt assessments, reflecting recipients' recollections of the general availability of social support and global satisfaction with this care. In contrast, a less often employed tactic is to measure received social support, a construct that assesses specific actions enacted as supportive behaviors [10,11]. Questionnaires measuring received social support ask recipients to give specific examples of recently received supportive behaviors.

Interestingly, the relationship between perceived and received social support is not well understood. Previous attempts to demarcate their unique contributions to health outcomes have proved inconclusive. Left as an open question at present is how, or even if, if received social support benefits individuals in unique ways relative to perceived social support [10-12]. We propose that one reason for this uncertainty lies in the units of analysis under investigation. Researchers may gain computational power by constraining the time frame for reporting by operationalizing both social support and health behaviors at similar levels of abstraction or specificity. We advise asking about received support, as concrete instantiations 
of support and health behaviors rather than perceived support, as indexed by global assessments and subjective generalizations. Moreover, we encourage measurement of received support on the daily level, repeatedly sampled over extended periods of time.

The match or mismatch in the specificity or generality of each variable may impact the predictive power of the model. Perceived social support is a relatively more abstract representation than received social support. As a result, perceived support may better predict subjective and global reports of personal health status rather than specific behavioral intentions for the coming day. The mismatch in specificity may reduce the strength of the statistical relationship between the two. Moreover, perceived support may reflect memory biases associated with encoding others' actions in light of active schemas [13]. For example, actions enacted by others that do not conform to the schema of a supportive partner would be better remembered than those that do conform [14]; as a result of biased memory reconstructions, gestalt summary statements like reports of perceived support may not accurately reflect reality experienced on a day to day basis, unless for instance, individuals are motivated to engage in more effortful reconstruction [15].

Scholz et al. [16] are some of the few researchers that have adopted our preferred measurement strategy. They studied the influence of received diet-specific social support on dietary behavior using a longitudinal approach [16]. At baseline, participants reported on received dietary social support over the last week using the Berlin Social Support Scale [17]. They also reported dietary intentions; however, those reflected global self-assessments of goals to eat healthier meals. Twelve months later, participants again reported on dietary intentions, in addition to fat-intake as indexed by reactions to three global statements including, "I follow a low-fat diet." Results indicated that baseline levels of received instrumental support predicted stronger intentions to eat a low-fat diet at follow-up for men, but not women, and reduced fat consumption at follow-up for both men and women. Baseline levels of emotional support had no influence on fat consumption at follow-up for women, but among men, greater emotional support predicted reduced fat consumption.

Although these findings provide support for the importance of received social support on diet, the level of specificity and generality of each variable may bear weight on the interpretation of the results. For instance, social support was operationalized at a fairly specific level. These researchers asked participants to recall specific instantiations of support behavior rather than relying on gestalt summaries. However, despite asking participants to recall specific actions, the time frame for reflection may induce complications that impair the accuracy of memory; it is difficult to accurately recall specific supportive behaviors that occurred over the course of seven days. Similarly, asking broad, subjective questions describing diet as a proxy for actual food consumption patterns increases the abstraction present and decreases the reliability and validity of the data itself [18]. For instance, those engaging in the least healthy behaviors may lack the knowledge to accurately report on whether they are in fact following a lowfat diet [19]. Moreover, people give themselves credit for their intentions when generating summary statements about abstract qualities and report more optimistically about themselves than their actual behavior warrants [20]. Measuring variables daily may moderate these retrospection biases [21]. And, considering the degree to which the specificity of predictor and outcome variables match may offer nuance to existing models.

\section{Conclusion}

In conclusion, social support plays a key role in promoting healthy behaviors. We suggest researchers consider the unit of analysis when assessing support and behavioral outcomes, and encourage adoption of daily measures of reflection on specific instances of both. Such an approach may foster greater or different insight into the social determinants of health-related behavior, and shed light on the best use of support systems for bolstering self-regulation in the diet and exercise domain.

\section{References}

1. IHRSA. Total number of memberships at fitness centers/health clubs in the U.S. from 2000 to 2016 (in millions). In Statista-The Statistics Portal.

2. Steverman B (2017) Why you're paying so much to exercise. Bloomberg.

3. Dray T (2017) Facts \& statistics about dieting. Live Strong. Com.

4. Finkelstein EA, Khaviou OA, Thompson H, Trogdon JG, Pan L, et al. (2012) Obesity and severe obesity forecasts through 2030. American Journal of Preventive Medicine 42(6): 563-570.

5. OECD (2017) OECD Health statistics 2017.

6. House JS, Robbins C, Metzner HL (1982) The association of social relationships and activities with mortality: Prospective evidence from the tecumseh community health study. American Journal of Epidemiology 116(1): 123-140.

7. Alpass FM, Neville S (2003) Loneliness, health and depression in older males. Aging Mental Health 7(3): 212-216.

8. Bramston P, Pretty G, Chipuer, H (2002) Unravelling subjective quality of life: An investigation of individual and community determinants. Social Indicators Research 59(3): 261-274.

9. Sallis JF, Grossman RM, Pinski RB, Patterson TL, Nader PR (1987) The development of scales to measure social support for diet and exercise behaviors. Prev Med 16(6): 825-836.

10. Haber MG, Cohen JL, Lucas T, Baltes BB (2007) The relationship between self-reported received and perceived social support: A metaanalytic review. Am J Community Psychol 39(1-2): 133-144.

11. Norris FH, Kaniasty K (1996) Received and perceived social support in times of stress: A test of the social support deterioration deterrence model. J Pers Soc Psychol 71(3): 498-511.

12. Dunkel SC, Bennett TL (1990) Differentiating the cognitive and behavioral aspects of social support. In: Sarason BR, Sarason IG, Pierce GR (Eds.), Social support: An interactional view, Wiley, New York, USA, pp. 267-296.

13. Bartlett FC (1932) Remembering: An experimental and social 
study. Cambridge: Cambridge University.

14. Davidson D (1994) Recognition and recall of irrelevant and interruptive atypical actions in script-based stories. Journal of Memory and Language 33(6): 757-775.

15. Ross M (1989) Relation of implicit theories to the construction of personal histories. Psychological review 96(2): 341-357.

16. Scholz U, Ochsner S, Hornung, R, Knoll N (2013) Does social support really help to eat a low-fat diet? Main effects and gender differences of received social support within the Health Action Process Approach. Appl Psychol Health Well Being 5(2): 270-290.

17. Schulz U, Schwarzer R (2003) Social support in coping with illness: The
Berlin Social Support Scales (BSSS). Diagnostica 49(2): 73-82.

18. Verbrugge LM (1980) Health diaries. Med Care 18(1): 73-95.

19. Kruger J, Dunning D (1999) Unskilled and unaware of it: How difficulties in recognizing one's own incompetence lead to inflated selfassessments. J Pers Soc Psychol 77(6): 1121-1134.

20. Balcetis E, Dunning D (2013) Considering the situation: Why people are better social psychologists than self-psychologists. Self and Identity 12(1): 1-15.

21. Iida M, Shrout PE, Laurenceau JP, Bolger N (2012) Using diary methods in psychological research. In: Cooper H, Camic PM, Long DL, Panter AT, Rindskopf D (Eds.), APA handbook of research methods in psychology,

\section{Your next submission with Juniper Publishers will reach you the below assets}

- Quality Editorial service

- Swift Peer Review

- Reprints availability

- E-prints Service

- Manuscript Podcast for convenient understanding

- Global attainment for your research

- Manuscript accessibility in different formats

( Pdf, E-pub, Full Text, Audio)

- Unceasing customer service

Track the below URL for one-step submission https://juniperpublishers.com/online-submission.php 